\title{
Effect of prior visual experience with a paradise fish (Macropodus opercularis) or a mirror image on strength of aggressive display in Siamese fighting fish (Betta splendens) toward a conspecific, an alien species (Macropodus opercularis), and a mirror image
}

\author{
WILLIAM M. MILEY, DOROTHY WETZEL, and JONATHAN BONDS \\ Richard Stockton State College, Ponoma, New Jersey 08240
}

\begin{abstract}
Betta splendens (Siamese fighting fish) were given 10 days of visual preexposure to either Macropodus opercularis (paradise fish) or their own mirror images. Separate groups of bettas were then allowed to display aggressively toward one of the following stimuli: a conspecific, an alien species (Macropodus opercularis), or a mirror image. Bettas displayed more frequently, and for a longer duration, when tested with either another betta or their own image than when tested with a macropodus. Bettas required more time to reach a criterion of no displays when tested with their own mirror image than when tested with the macropodus fish; this measure did not differ between the betta test condition and the macropodus test condition. Strength of aggressive displays in bettas is dependent of previous exposure conditions (Miley \& Burack, 1977), the particular stimuli used in behavioral testing, and measures used in recording the aggressive response.
\end{abstract}

Betta splendens are well known for their aggressive behavior toward conspecifics and toward highly responsive fish, such as Macropodus opercularis, with which they are tested (Braddock \& Braddock, 1958; R. N. Johnson \& L. D. Johnson, 1973). When a male betta is placed in visual isolation and then tested with a mirror in which he presumably sees his own image, he displays more frequently than do bettas not visually isolated (Clayton \& Hinde, 1968; Hinkel \& Maier, 1974). Other studies have shown that previous visual isolation produces a higher frequency of displays in bettas to other responsive bettas with which they are later tested than to macropodus fish (H. G. Johnson \& Peeke, 1972; Miley \& Burak, 1977), but that previous visual exposure to bettas increases the latency to first display to responsive bettas with which they are later tested compared with a mirror image or a macropodus fish (Miley \& Burack, 1977). However, when a measure of mean duration of aggressive display was obtained for previously isolated bettas tested in the above conditions, this measure showed no differences between a betta or a macropodus fish used as a test stimulus (R. N. Johnson \& L. D. Johnson, 1973; Miley \& Burack, 1977). These results suggest that it is difficult to state that, in general, intraspecific aggression is much more frequent than inter-

This research was supported by a research and professional development grant from the state of New Jersey. We wish to thank J. V. Lambert and J. Blustein for valuable ideas and data analyses aid, respectively. specific aggression (i.e., Lorenz, 1966) without considering the previous experiences of animals and the response measures used in recording the aggressive responses.

The present experiment extended the investigation initiated by Miley and Burack (1977) of prior social (visual) experience on the strength of aggressive display (as measured by latency to first display, number and duration of displays, and time to an absence of responding for $15 \mathrm{~min}$ ) in bettas toward a conspecific, a mirror image, and an alien species (Macropodus opercularis). In the present experiment, prior visual experience was extended from an isolation condition and a betta condition used in the Miley and Burak (1977) study to a mirror condition and a macropodus fish condition.

\section{METHOD}

\section{Subjects}

The subjects were 60 naive adult male Betta splendens. The fish used as stimuli were 50 naive adult male Macropodus opercularis and 20 naive adult male bettas. All fish were obtained from a local supplier. The stimulus fish were visually isolated from other animals for 10 days prior to their use in behavioral testing. All fish were fed Tetra-Min in the morning at least $2 \mathrm{~h}$ prior to behavioral testing, and once a week, they received brine shrimp. All fish were exposed to a 12-h light-dark cycle. Water temperature was maintained at approximately $25^{\circ} \mathrm{C}$ throughout the experiment.

Upon arrival in the laboratory, each experimental betta was placed in a $250-\mathrm{ml}$ clear beaker and randomly assigned to an experimental group of 10 in a 2 by 3 design. Bettas in three of the groups were exposed to their mirror images for 10 days 
prior to behavioral testing ( $M$ groups), and bettas in the other three groups were exposed to a macropodus in a $250-\mathrm{ml}$ clear beaker next to theirs for these 10 days ( $P$ groups). During behavioral testing, 10 bettas in the $M$ groups (Group MB) and 10 bettas in the P groups (Group PB) were exposed to another betta in the test situation, 10 bettas in the M groups (Group MM) and 10 bettas in the $P$ groups (Group PM) were exposed to mirror images, and 10 bettas in the $M$ groups (Group MP) and 10 bettas in the $P$ groups (Group PP) were exposed to a macropodus.

\section{Apparatus}

All fish were housed in $250-\mathrm{ml}$ beakers. The behavioral testing tank $(20 \times 10 \times 10 \mathrm{~cm})$ was divided into two $(10 \times 10$ $x 10 \mathrm{~cm})$ chambers separated by a clear glass divider $(10 \times 10 \mathrm{~cm})$ that permitted both visual and chemical communication. On the side opposite to the experimental betta was placed either a simulus fish or a stimulus mirror that covered the area of the tank. The mirror and the glass divider were completely covered by an opaque partition that was removed when the test period began. Testing occurred in an environmental chamber that maintained a constant temperature of $25^{\circ} \mathrm{C}$.

\section{Procedure}

Following 10 days of exposure to either a mirror image or a macropodus, each experimental betta was placed in the divided fish tank. The observer was not aware of the preexposure group to which each experimental betta belonged, to control for any observer bias. If the stimulus was another fish, the stimulus was placed on the other side of the tank at the same time as the experimental betta. The opaque partition was used to keep the experimental bettas visually isolated from the stimulus (another betta, the mirror, or a macropodus) for 30 min of adaptation. Following adaptation, the opaque divider was removed, the experimental betta was exposed to a stimulus, and behavioral recording began. The test condition was randomized on the day of testing to minimize observer order effects. Aggressive displays were defined as a front or side orientation toward the stimulus and extension of the gill covers. Latency to initial display, frequency and duration of displays, and total time to a criterion of no displays for $15 \mathrm{~min}$ were recorded on an Esterline-Angus Minigraph (Model E00704B2074) by key. If an animal did not display, it was assigned maximum latency $(90 \mathrm{~min})$. The testing period ended in $90 \mathrm{~min}$ whether or not the experimental betta was still displaying at this time.

\section{RESULTS AND DISCUSSION}

The means and standard errors of the mean for the dependent measures are presented in Table 1. Because of the large variation in the behavioral measures, squareroot transformations were performed before a 2 by 3 factorial analysis was performed on each measure. Tukey's tests were used for all post hoc pairwise comparisons of means. As seen in Table 1, significant differences occurred in the frequency and duration measures and in the time-to-criterion measure. All significant effects occurred between behavioral test conditions (ps<.05); neither the preexposure condition nor any interaction was significant (ps $>.05$ ).

The data from this experiment show that visual preexposure to a mirror or to an alien species (Macropodus opercularis) does not differentially affect the strength of the aggressive display in bettas in any of the test conditions. However, the frequency and duration measures show less responsiveness to the alien species than to conspecifics and mirror images. Using conditions similar to the present experiment, the data from the Miley and Burack (1977) study showed that bettas visually preexposed to a conspecific required longer to initiate the first display to bettas with which they were tested, compared with a mirror image or a macropodus testing condition; visually isolated bettas showed increased frequencies to test bettas compared with the other test conditions. No other behavioral measures showed significant differences. This study and the Miley and Burack study suggest that the frequency measure is more likely to vary from the visual preexposure and test conditions in these experiments than is the duration measure. These results reinforce Figler's (1972) view that frequency measures seem to operate along a different time dimension than do duration measures under identical testing conditions.

The present study also shows that bettas viewing their own images are more persistent in their displays on the measure of time to a criterion of no displays. Viewing conspecifics occupied a middle position on this measure, differing from neither the mirror image condition nor the macropodus condition. These results confirm Baenninger's (1966) observation that bettas display most vigorously when viewing their own images.

In addition, the threat-display measure used here and actual fighting vary independently of each other (Cain, Anderson, Stein, \& Jessen, 1980; Meliska, Meliska, \& Peeke, 1980).

In summary, we believe that it is difficult to state

Table 1

Mean Latency to First Display (LFD), Mean Frequency of Displays (FD), Mean Duration of Displays (DD), and Mean Time to a Criterion of No Displays for 15 Min (CND) in the Six Experimental Betta Groups

\begin{tabular}{|c|c|c|c|c|c|c|c|c|c|}
\hline \multirow[b]{2}{*}{ Group } & \multirow[b]{2}{*}{$\mathrm{N}$} & \multicolumn{2}{|c|}{ LFD (in Minutes) } & \multicolumn{2}{|c|}{ FD } & \multicolumn{2}{|c|}{ DD (in Minutes) } & \multicolumn{2}{|c|}{ CND (in Minutes) } \\
\hline & & Mean & SEM & Mean & SEM & Mean & SEM & Mean & SEM \\
\hline MB & 10 & 20.15 & 11.69 & 126.70 & 44.99 & 11.12 & 3.83 & 58.26 & 11.49 \\
\hline PB & 10 & 36.72 & 14.50 & 152.10 & 77.99 & 8.51 & 4.61 & 46.33 & 11.92 \\
\hline MM & 10 & 19.00 & 11.84 & 162.80 & 49.92 & 10.43 & 2.64 & 67.92 & 11.25 \\
\hline PM & 10 & 9.69 & 8.93 & 197.40 & 57.33 & 17.15 & 5.49 & 64.17 & 10.64 \\
\hline MP & 10 & 45.51 & 14.83 & $15.10^{*}$ & 8.91 & $1.42 *$ & 1.12 & $26.68 \dagger$ & 4.86 \\
\hline PP & 10 & 36.18 & 14.65 & $15.80^{*}$ & 6.20 & $1.17^{*}$ & .49 & $29.92 \dagger$ & 8.42 \\
\hline
\end{tabular}

*Test Condition $P$ differs from Test Conditions $M$ and $B$. $\quad$ †Test Condition P differs from Test Condition M. 
that intraspecific aggression is much more frequent than interspecific unless the conditions leading up to behavioral testing, and the behavioral measures recorded, are carefully considered.

\section{REFERENCES}

Baenninger, R. Waning of aggressive motivation in Betta splendens. Psychonomic Science, 1966, 4, 241-242.

Braddock, J. D., \& Braddock, A. J. Effects of isolation and social contact upon the development of aggressive behavior in Siamese fighting fish, Betta splendens. Animal Behaviour, 1958, 6, 249.

Cain, N. W., Anderson, R., Stein, L., \& Jessen, C. Effects of prior social experience on agonistic responding by Siamese fighting fish (Betta splendens). Animal Learning \& Behavior, $1980,8,491-496$.

Clayton, F. L., \& Hinde, R. A. The habituation and recovery of aggressive display in Betta splendens. Behaviour, 1968, 30, 96-106.

FIGLER, M. The relation between eliciting stimulus strength and habituation of the threat display in male Siamese fighting fish, Betta splendens. Behaviour, 1972, 42, 63-96.

HinkEL, T. J., \& MAIER, R. Isolation and aggression in Siamese fighting fish. Psychological Reports, 1974, 34, 1323-1326.

Johnson, H. G., \& Peeke, H. V. S. Patterns of intra- and interspecific aggression in labyrinth fish (Belontiidae). Behavioral Biology, 1972, 7, 335-348.

Johnson, R. N., \& Johnson, L. D. Intra- and interspecific social and aggressive behaviour in Siamese fighting fish, Betta splendens. Animal Behaviour, 1973, 21, 665-672.

LoREnZ, K. On aggression. London: Methuen, 1966.

Meliska, C. J., Meliska, J. A., \& Peeke, H. V. S. Threat displays and combat aggression in Betta splendens following visual exposure to conspecifics and one-way mirrors. Behavioral and Neural Biology, 1980, 28, 473-486.

Miley, W. M., \& BuraCK, G. Strength of aggressive display in Siamese fighting fish (Betta splendens) toward a conspecific, an alien species (Macropodus opercularis), and a mirror image as affected by prior conspecific visual experience. Behavioral Biology, 1977, 21, 267-272.

(Received for publication November 13, 1980.) 